\title{
New-Fangled Mandelbrot and Julia Sets for Logarithmic Function
}

\author{
Suraj Singh Panwar \\ M.Tech. - CSE, Scholar \\ Faculty of Technology, \\ Computer Science and Engineering Department, \\ Uttarakhand Technical University, Dehradun
}

\begin{abstract}
In this paper we explore the dynamics of complex logarithmic function for integer and non-integer values. We have used Ishikawa iteration method for generating fractals and analyzed them.
\end{abstract}

\section{Keywords}

Fractals, Mandelbrot set, Julia set, Mann Iteration, Ishikawa Iteration, Computer Graphics, Fixed point and Graph.

\section{INTRODUCTION}

Fractal Theory is an exciting branch of applicable Mathematics and Computer Science. It is based on the concept of self-similar forms. Benoit Mandelbrot (1924-2010), scientist and mathematician who also worked at IBM, is known as the father of fractal geometry. Mandelbrot coined the word fractal in the late 1970s. Mandelbrot published to explain geometric fractals as "a rough or fragmented geometric shape that can be divided into parts, every one of which is a reduced-size duplicate of the whole".[1] There are many sort of fractals found in nature. Fractals are all around us in the form of many usual objects such as mountains, coastlines, trees ferns and clouds [2,3,4]. They all are fractals in nature and can be represented on a computer by a recursive algorithm of computer graphics. Before the innovation of computers, Fractals have appeared as an important question. Fractal is defined as a set, which is selfsimilar under magnification.[5]

The Julia sets and the Mandelbrot sets are two most important objects under various researches in the field of fractal theory [6]. The Julia set was given by French mathematician Gaston Julia (1893-1978) in 1918, whereas the Mandelbrot set was given by Benoit B. Mandelbrot (1924-2010) in 1979.

\section{PRELIMINARIES}

\subsection{Mann's Iteration: One Step Iteration}

Mann's iteration technique is a one-step iteration technique given by William Robert Mann (1920-2006), a mathematician from Chapel Hill, North Carolina. The iteration technique involves one step for iteration, and is given as $[7,8]$ :

$$
x_{n+1}=(1-s) x_{n}+s . f\left(x_{n}\right),
$$$$
\text { where } \mathrm{n} \geq 0 \text { and } 0<\mathrm{s}<1
$$

\subsection{Ishikawa Iteration : Two Step Iteration}

Ishikawa iteration $[9,10]$ technique is a two-step iteration method known after Ishikawa. Let $\mathrm{X}$ be a subset of complex number and $f: X \rightarrow X$ for all $x_{0} \in X$, we have the sequence numbers for $\left\{\mathrm{x}_{\mathrm{n}}\right\}$ and $\left\{\mathrm{y}_{\mathrm{n}}\right\}$ in $\mathrm{X}$ according to following way. $[11,12]$ :

\author{
Pawan Kumar Mishra \\ Assistant Professor, M.Tech. CSE \\ Faculty of Technology, \\ Computer Science and Engineering Department, \\ Uttarkhand Technical University, Dehradun

$$
\begin{aligned}
& y_{n}=S^{\prime}{ }_{n} f\left(x_{n}\right)+\left(1-S^{\prime}{ }_{n}\right) x_{n} \\
& x_{n+1}=S_{n} f\left(y_{n}\right)+\left(1-S_{n}\right) x_{n}
\end{aligned}
$$

Where, $0 \leq \mathrm{S}_{\mathrm{n}} \leq 1,0 \leq \mathrm{S}_{\mathrm{n}} \leq 1$ and $\mathrm{S}_{\mathrm{n}}{ }_{\mathrm{n}} \& \mathrm{~S}_{\mathrm{n}}$ are both convergent to non-zero number.

\section{GENERATION OF RELATIVE SUPERIOR MANDELBROT SETS}

We present here some Relative Superior Mandelbrot sets for the function $\mathrm{Z} \rightarrow \log \left(\mathrm{Z}^{\mathrm{n}}+\mathrm{C}\right), \mathrm{n}>=2.0$, for integer and some noninteger values. Process of generating fractal images is similar to self-squared function $[13,14,15]$. The parameter s and s' also changes the structure and beauty of fractals.

\subsection{Relative Superior Mandelbrot sets for Quadratic function:}

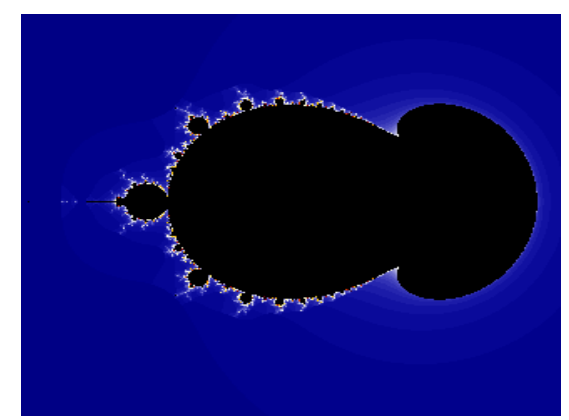

Figure. 1 Relative Superior Mandelbrot set for $s=s,=1, n=2$

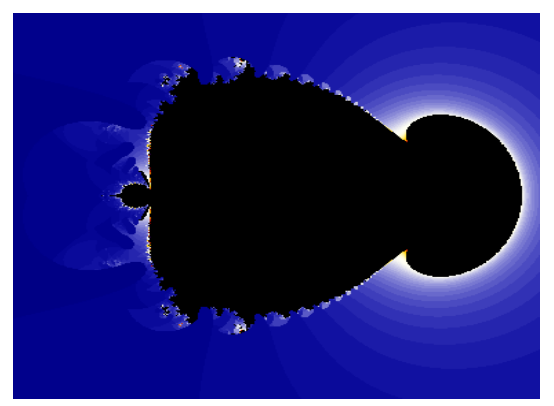

Figure 2 Relative Superior Mandelbrot set for $\mathrm{s}^{\mathrm{s}} \mathrm{s}^{\prime}=\mathbf{0 . 5 , \mathrm { n } = 2}$ 


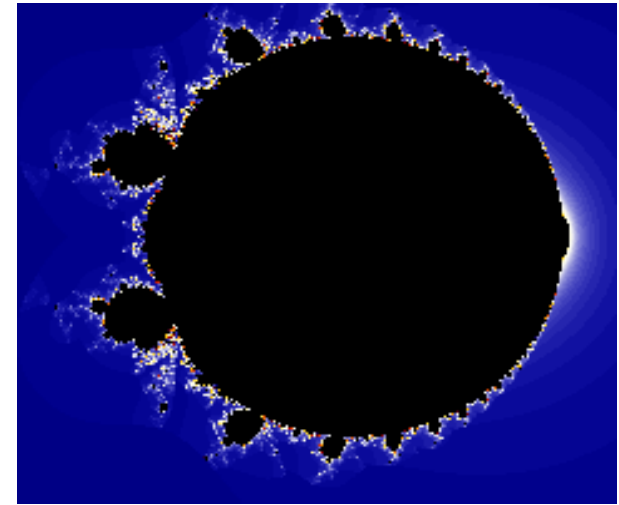

Figure 3 Relative Superior Mandelbrot set for $s=s,=1, n=2.4$

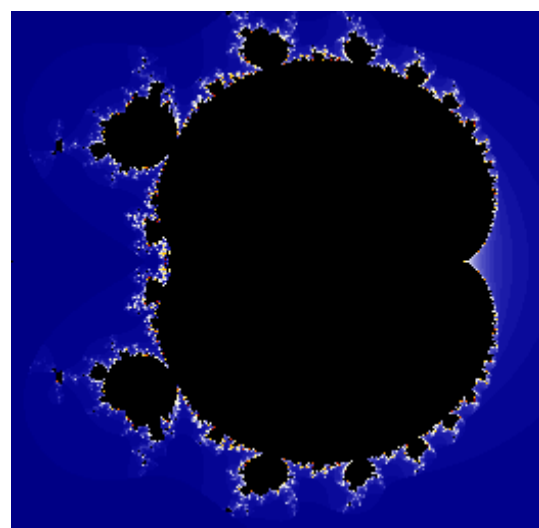

Figure 4 Relative Superior Mandelbrot set for $s=s^{\prime}=1, n=2.8$

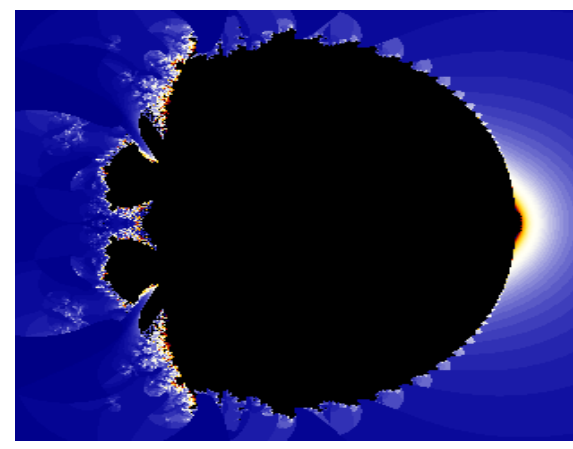

Figure 5 Relative Superior Mandelbrot set for $\mathrm{s}^{\mathrm{s}}=\mathbf{s}=\mathbf{0 . 5}$, $\mathrm{n}=\mathbf{2 . 4}$

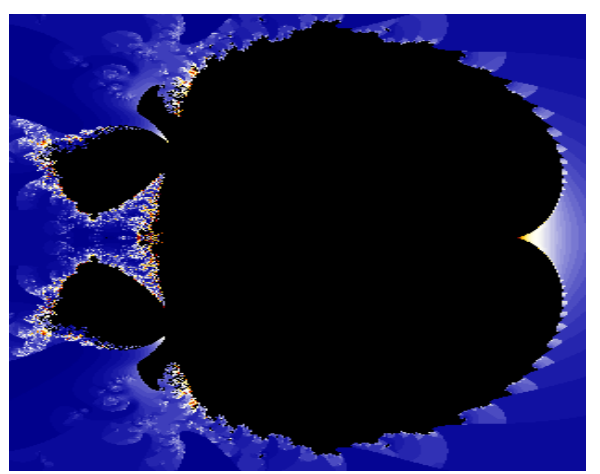

Figure 6 Relative Superior Mandelbrot set for $\mathrm{s}=\mathrm{s}^{\prime}=\mathbf{0 . 5}, \mathrm{n}=\mathbf{2 . 8}$

\subsection{Relative Superior Mandelbrot set for Cubic function.}

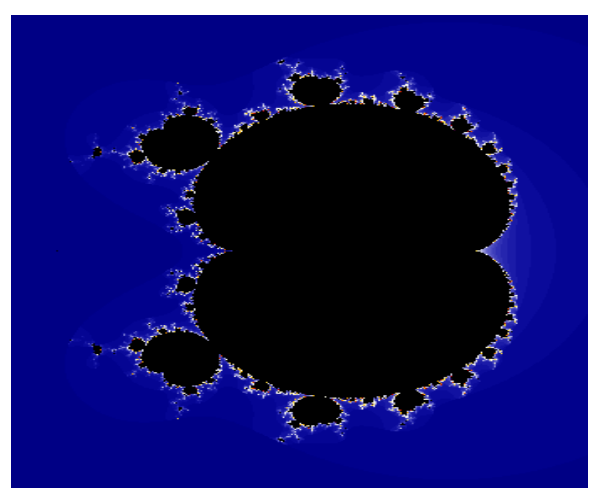

Figure 7 Relative Superior Mandelbrot set for $\mathbf{s}^{=} \mathbf{s}^{\prime}=\mathbf{1}, \mathbf{n}=\mathbf{3}$.

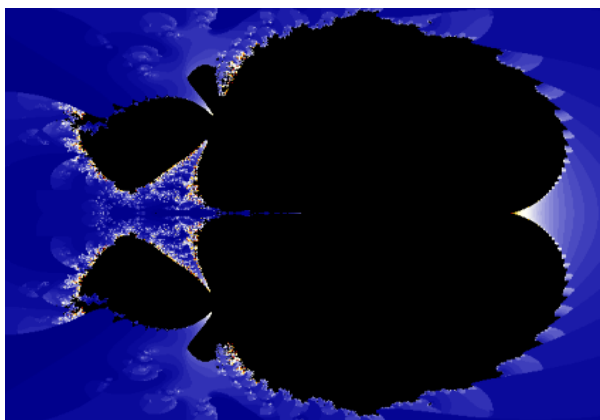

Figure 8 Relative Superior Mandelbrot set for $s=s^{\prime}=0.5, n=3$

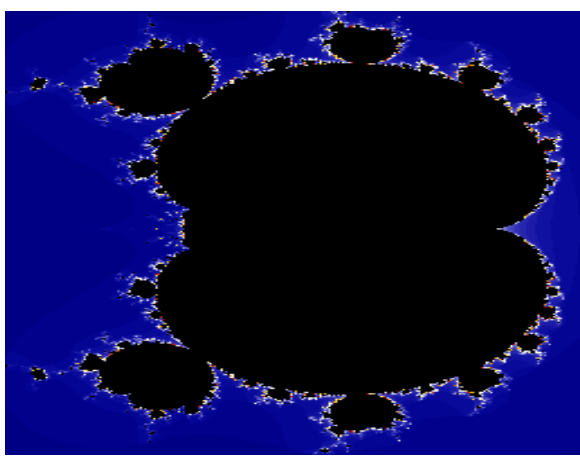

Figure 9 Relative Superior Mandelbrot set for $s^{\prime}=s^{\prime}=1, n=3.4$

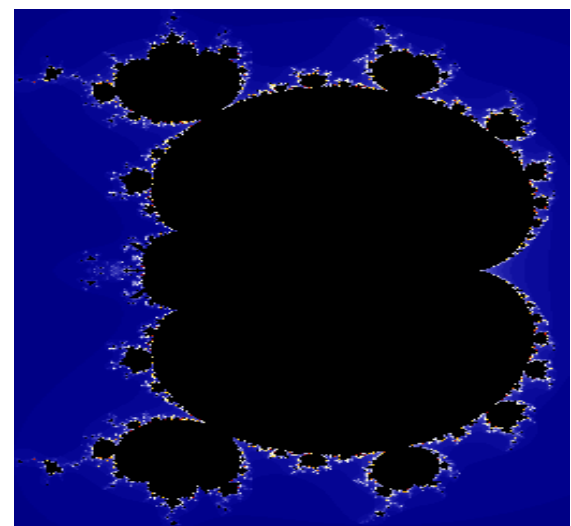

Figure 10 Relative Superior Mandelbrot set for $\mathrm{s}=\mathbf{s}^{\prime}=\mathbf{1 , n}=\mathbf{3 . 8}$ 


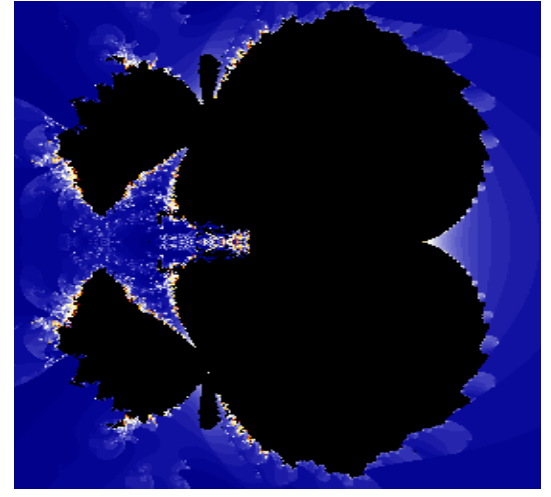

Figure 11 Relative Superior Mandelbrot set for $\mathrm{s}=\mathrm{s}^{\prime}=\mathbf{0 . 5}, \mathrm{n}=3.4$

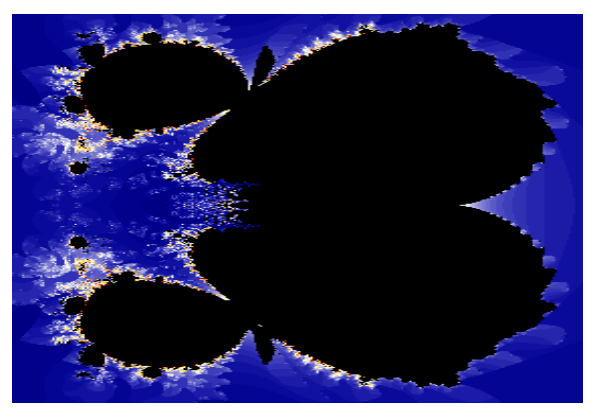

Figure 12 Relative Superior Mandelbrot set for $\mathrm{s}=\mathrm{s}^{\prime}=\mathbf{0 . 5}, \mathrm{n}=3.8$

\subsection{Relative Superior Mandelbrot set for Bi-} Quadratic function.

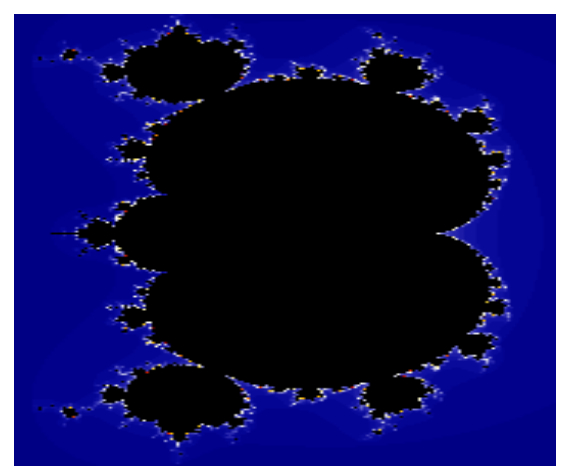

Figure 13 Relative Superior Mandelbrot set for $s=s,=1, n=4$

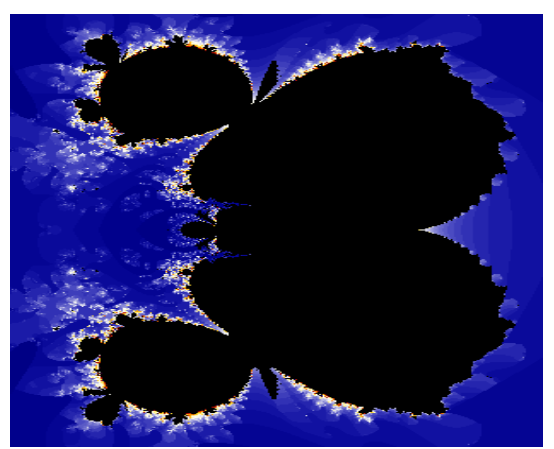

Figure 14 Relative Superior Mandelbrot set for $\mathrm{s}=\mathrm{s}^{\prime}=0.5, \mathrm{n}=4$

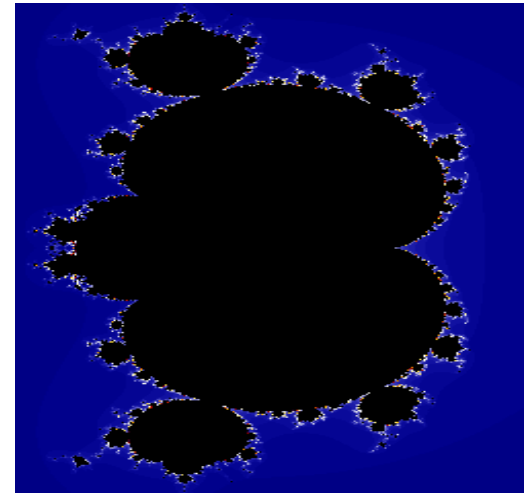

Figure 15 Relative Superior Mandelbrot set for $\mathrm{s}^{\prime}=\mathrm{s}^{\prime}=1, \mathrm{n}=4.4$

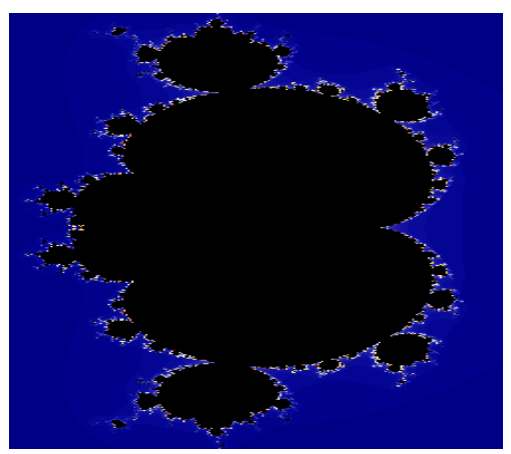

Figure 16 Relative Superior Mandelbrot set for $\mathrm{s}^{\prime}=\mathrm{s}^{\prime}=1, \mathrm{n}=4.8$

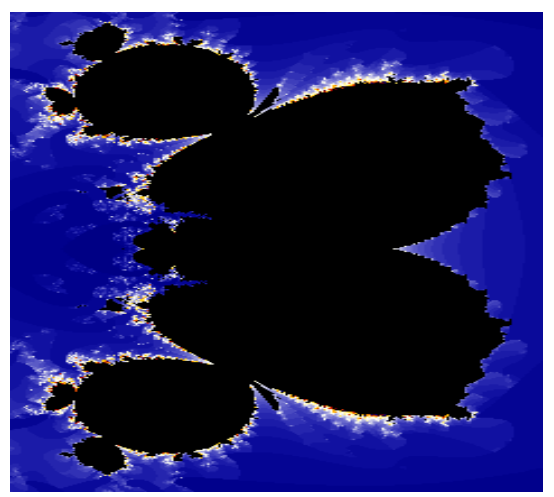

Figure 17 Relative Superior Mandelbrot set for $\mathrm{s}=\mathrm{s}^{\prime}=\mathbf{0 . 5 , n = 4 . 4}$

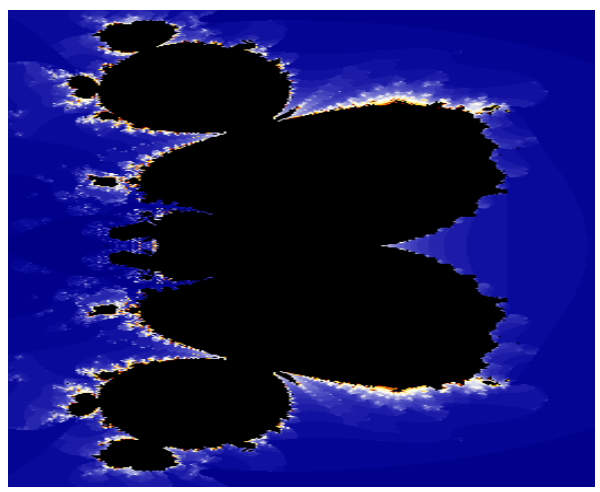

Figure 18 Relative Superior Mandelbrot set for $\mathrm{s}=\mathrm{s}^{\prime}=\mathbf{0 . 5}, \mathrm{n}=4.8$ 


\subsection{Generalization of Relative Superior}

Mandelbrot sets:-

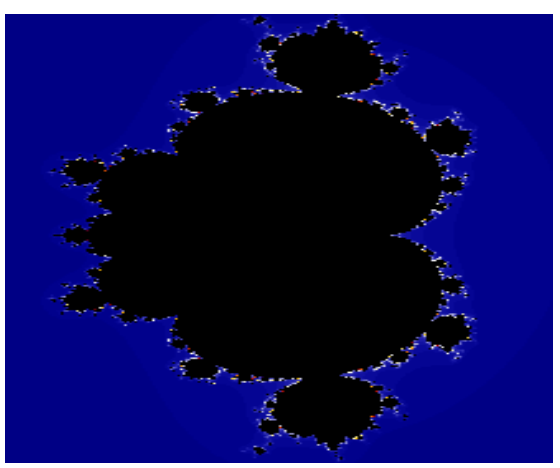

Figure 19 Relative Superior Mandelbrot set for $s=s '=1, n=6$

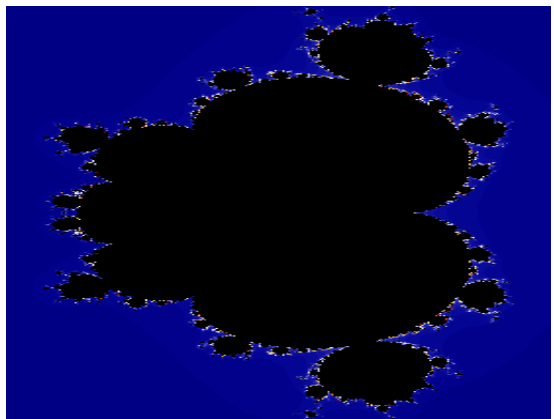

Figure 20 Relative Superior Mandelbrot set for $s=s^{\prime}=1, n=6.5$

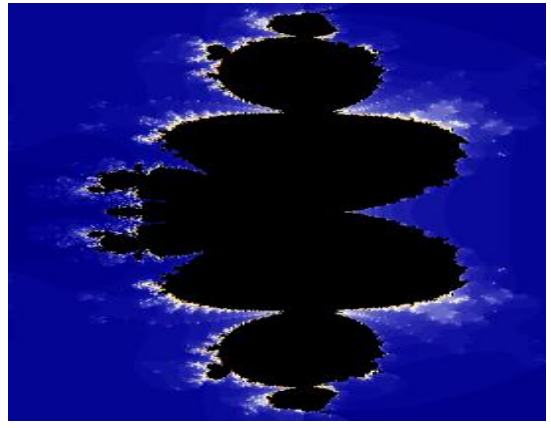

Figure 21 Relative Superior Mandelbrot set for $\mathrm{s}^{\prime} \mathrm{s}^{\prime}=0.5, \mathrm{n}=6$

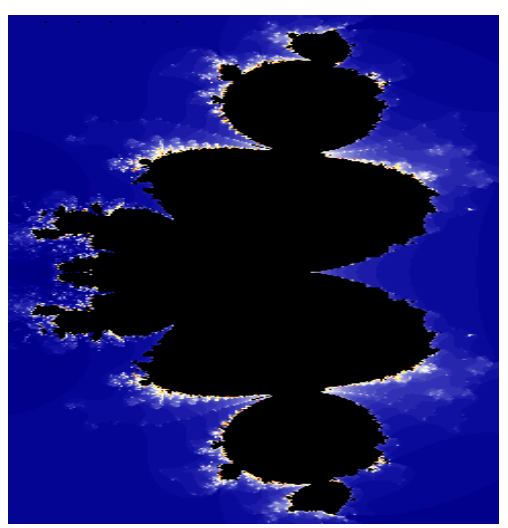

Figure 22 Relative Superior Mandelbrot set for $\mathrm{s}=\mathrm{s}^{\prime}=0.5, \mathrm{n}=6.5$

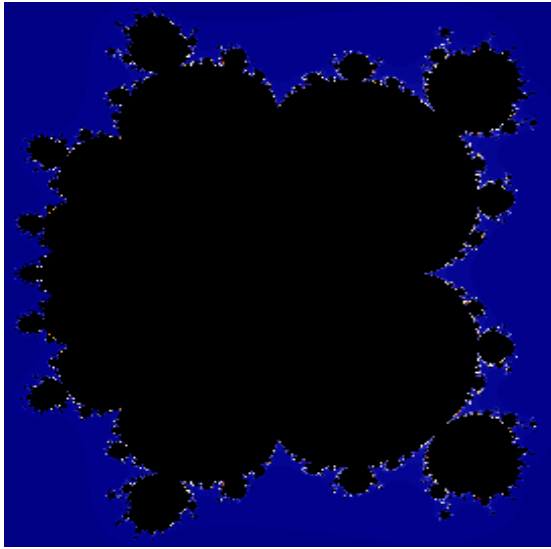

Figure 23 Relative Superior Mandelbrot set for $s=s^{\prime}=1, n=10$

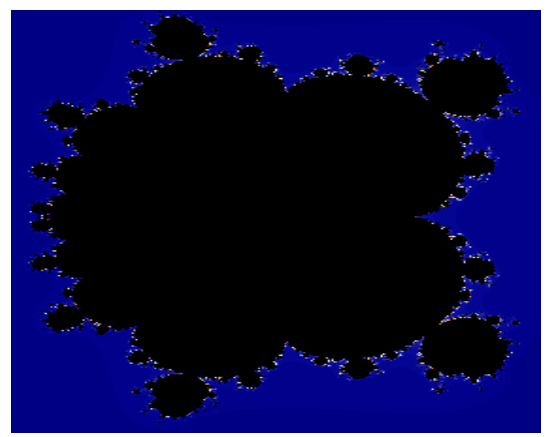

Figure 24 Relative Superior Mandelbrot set for $\mathrm{s}=\mathrm{s}^{\prime}=1, \mathrm{n}=10.5$

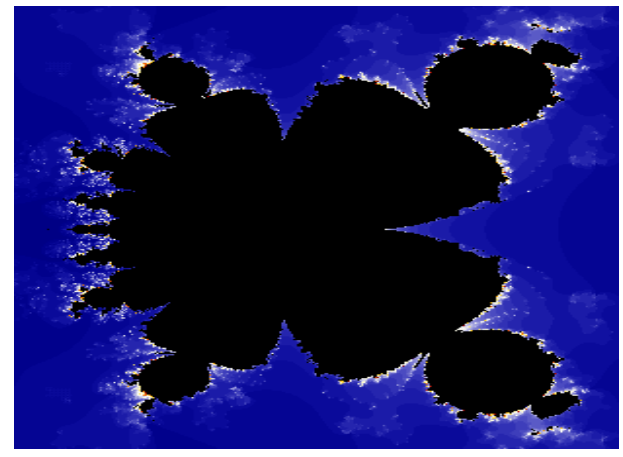

Figure 25 Relative Superior Mandelbrot set for $\mathrm{s}=\mathrm{s}^{\prime}=\mathbf{0 . 5}, \mathrm{n}=10$

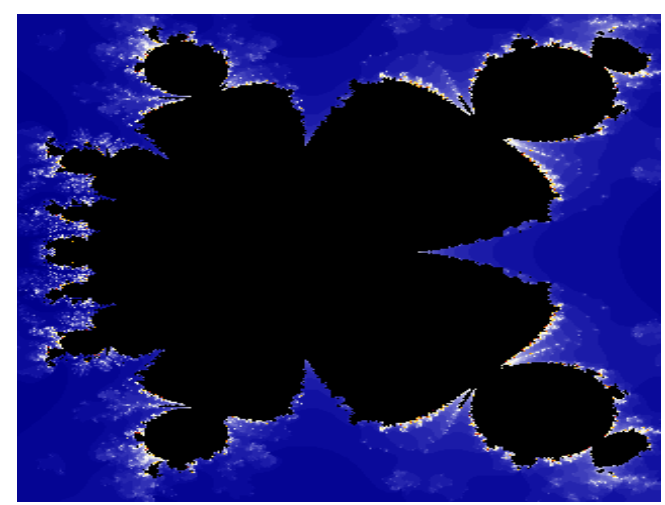

Figure 26 Relative Superior Mandelbrot set fors $=s^{\prime}=0.5, n=10.5$ 


\section{GENERATION OF RELATIVE SUPERIOR JULIA SETS}

We present here some Relative Superior Julia sets for the function $Z \rightarrow \log \left(Z^{n}+C\right), n>=2.0$, for integer and some noninteger values. The parameter $s$ and s' also changes the structure and beauty of fractals. Following are some of the Julia sets for quadratic, cubic and bi-quadratic functions.

\subsection{Relative Superior Julia sets for}

Quadratic function.

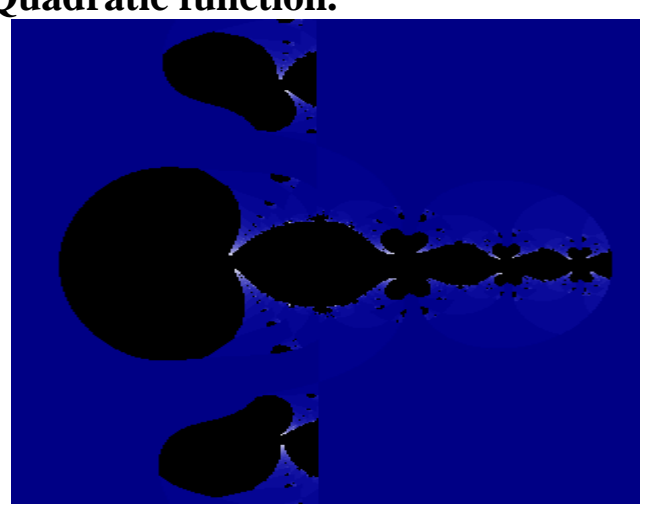

Figure 27 RSJS for $\mathrm{s}=\mathrm{s}^{\prime}=\mathbf{0 . 5}, \mathrm{n}=\mathbf{2}, \mathrm{c}=\mathbf{0 . 2 1 5 2 7 7 7 8 +}$ $0.00694444 i$

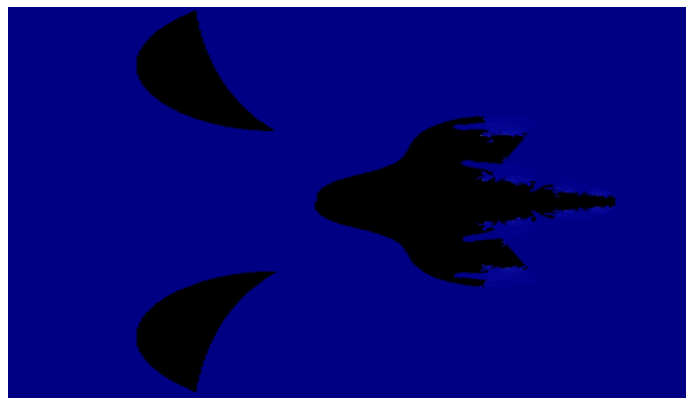

Figure 28 RSJS for $\mathrm{s}^{=}=\mathrm{s}^{\prime}=.5, \mathrm{n}=\mathbf{2 . 5} \mathrm{c}=\mathbf{0 . 2 1 5 2 7 7 7 7 7 8 +}$ $0.0069444444 i$

\subsection{Relative Superior Julia sets for Cubic} function.

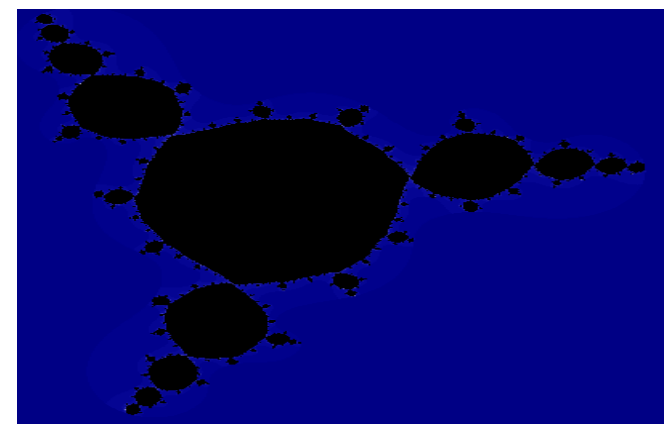

Figure 29 RSJS for $s^{\prime}=s^{\prime}=1, n=3 \mathrm{c}=0.5234-0.6319 i$

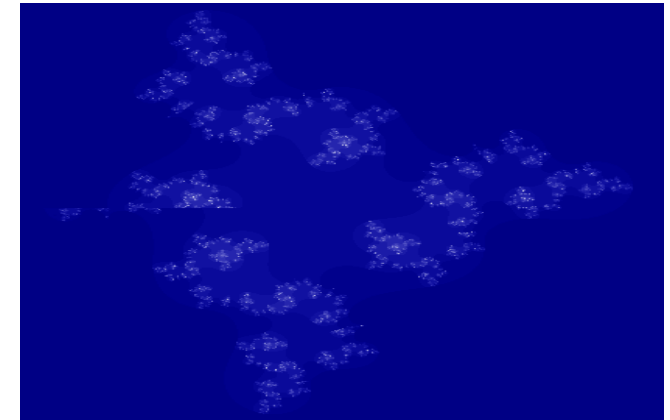

Figure 30 RSJS for $s^{\prime}=s^{\prime}=1, n=3.5 c=0.5234-0.6319 i$

4.3 Relative Superior Julia sets for BiQuadratic function.

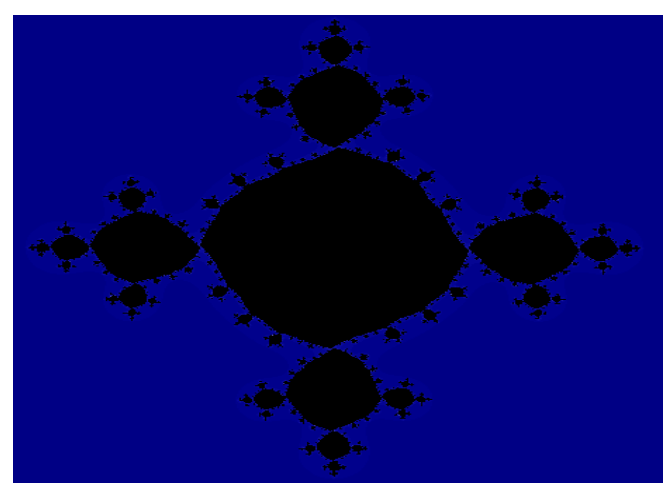

Figure 31 RSJS for $s^{\prime}=s^{\prime}=1, n=4 c=0.423611+0.01388 i$

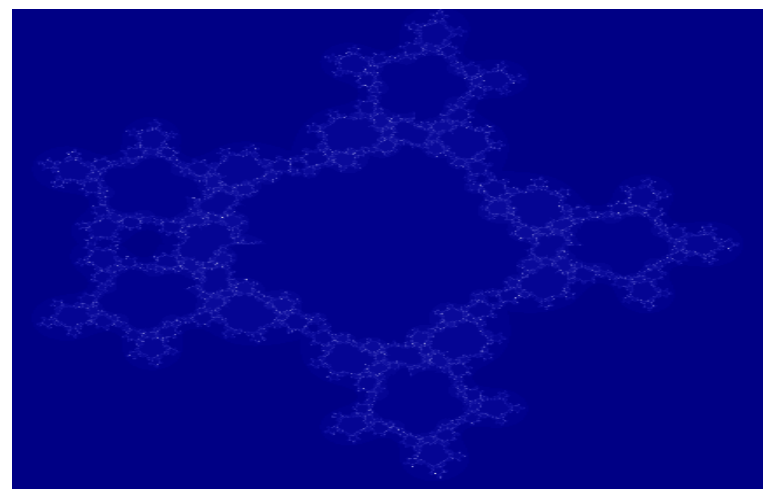

Figure 32 RSJS for $\mathrm{s}^{\prime} \mathrm{s}^{\prime}=1, \mathrm{n}=4.5 \mathrm{c}=\mathbf{0 . 4 2 3 6 1 1}+\mathbf{0 . 0 1 3 8 8 \mathrm { i }}$

\section{FIXED POINTS AND GRAPHS}

5.1 Fixed points of quadratic polynomials

Table 1: Orbit of $F(z)$ at $s=s^{\prime}=0.5, n=2$ for $z_{0}=0.21527778+$ 0.00694444

\begin{tabular}{|c|c|c|c|}
\hline No. of iteration & $|\mathrm{F}(\mathrm{z})|$ & No. of iteration & $|\mathrm{F}(\mathrm{z})|$ \\
\hline 25 & 2.5344 & 35 & 2.5400 \\
\hline 26 & 2.5355 & 36 & 2.5401 \\
\hline 27 & 2.5364 & 37 & 2.5400 \\
\hline 28 & 2.5376 & 38 & 2.5399 \\
\hline
\end{tabular}




\begin{tabular}{|c|c|c|c|}
\hline 29 & 2.5381 & 39 & 2.5399 \\
\hline 30 & 2.5390 & 40 & 2.5398 \\
\hline 31 & 2.5392 & 41 & 2.5398 \\
\hline 32 & 2.5398 & $\mathbf{4 2}$ & $\mathbf{2 . 5 3 9 7}$ \\
\hline 33 & 2.5398 & 43 & 2.5397 \\
\hline 34 & 2.5401 & 44 & 2.5397 \\
\hline
\end{tabular}

We skipped 24 Iterations and after 42 iterations value converges to a fixed point.

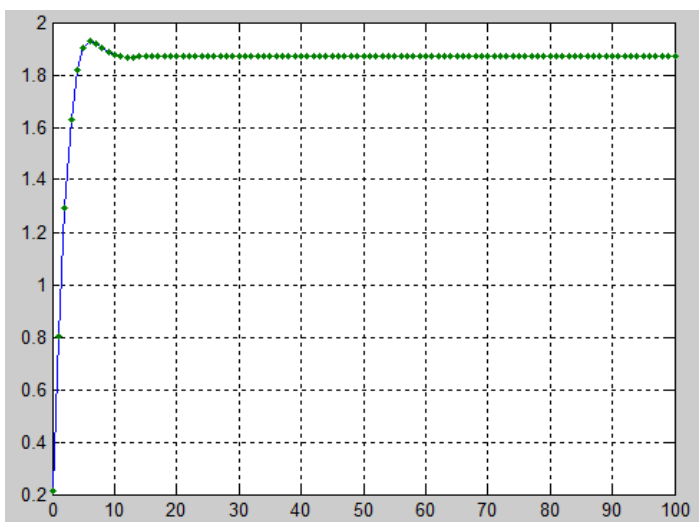

Figure 33 Orbit of $F(z)$ at $s=s^{\prime}=0.5, n=2$ for $z_{0}=0.21527778+$ $0.00694444 i$

Table 2 : Orbit of $F(z)$ at $s^{\prime}=s^{\prime}=0.5, \quad n=2.5$ for $\mathrm{z}_{0}=0.21527778+0.00694444 \mathrm{i}$

\begin{tabular}{|c|c|c|c|}
\hline No. of iteration & $|\mathrm{F}(\mathrm{z})|$ & No. of iteration & $|\mathrm{F}(\mathrm{z})|$ \\
\hline 103 & 2.8276 & 114 & 2.8280 \\
\hline 104 & 2.8277 & 115 & 2.8280 \\
\hline 105 & 2.8277 & 116 & 2.8280 \\
\hline 106 & 2.8278 & 117 & 2.8280 \\
\hline 107 & 2.8278 & 118 & 2.8280 \\
\hline 108 & 2.8279 & 119 & 2.8280 \\
\hline 109 & 2.8279 & 120 & 2.8280 \\
\hline 110 & 2.8280 & 121 & 2.8280 \\
\hline 111 & 2.8280 & $\mathbf{1 2 2}$ & $\mathbf{2 . 8 2 7 9}$ \\
\hline 112 & 2.8280 & 123 & 2.8279 \\
\hline 113 & 2.8280 & 124 & 2.8279 \\
\hline
\end{tabular}

We skipped 102 Iterations and after 122 iterations value converges to a fixed point.

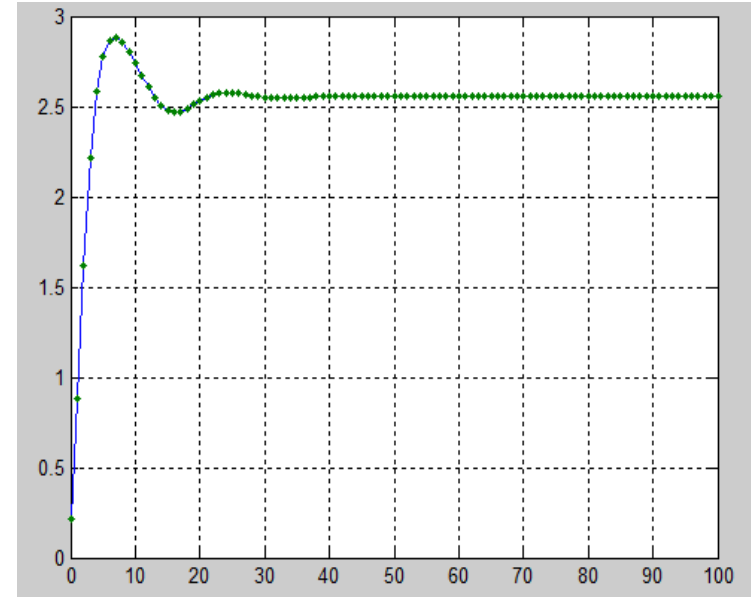

Figure 34 Orbit of $F(z)$ at $s=s^{\prime}=0.5, n=2.5$ for $\mathrm{z}_{0}=0.21527778+0.00694444 \mathrm{i}$

\subsection{Fixed points of Cubic polynomials}

Table 3: Orbit of $F(z)$ at $s=s^{\prime}=1, n=3$ for $z_{0}=0.5234-0.6319 i$

\begin{tabular}{|c|c|c|c|}
\hline No. of iteration & $|\mathrm{F}(\mathrm{z})|$ & No. of iteration & $|\mathrm{F}(\mathrm{z})|$ \\
\hline 13 & 4.5084 & 23 & 4.4869 \\
\hline 14 & 4.5014 & 24 & 4.4867 \\
\hline 15 & 4.4967 & 25 & 4.4866 \\
\hline 16 & 4.4934 & 26 & 4.4866 \\
\hline 17 & 4.4912 & 27 & 4.4865 \\
\hline 18 & 4.4896 & 28 & 4.4865 \\
\hline 19 & 4.4886 & 29 & 4.4865 \\
\hline 20 & 4.4879 & $\mathbf{3 0}$ & $\mathbf{4 . 4 8 6 4}$ \\
\hline 21 & 4.4874 & 31 & 4.4864 \\
\hline 22 & 4.4871 & 32 & 4.4864 \\
\hline
\end{tabular}

We have skipped 12 Iterations and after 30 iterations value converges to a fixed point.

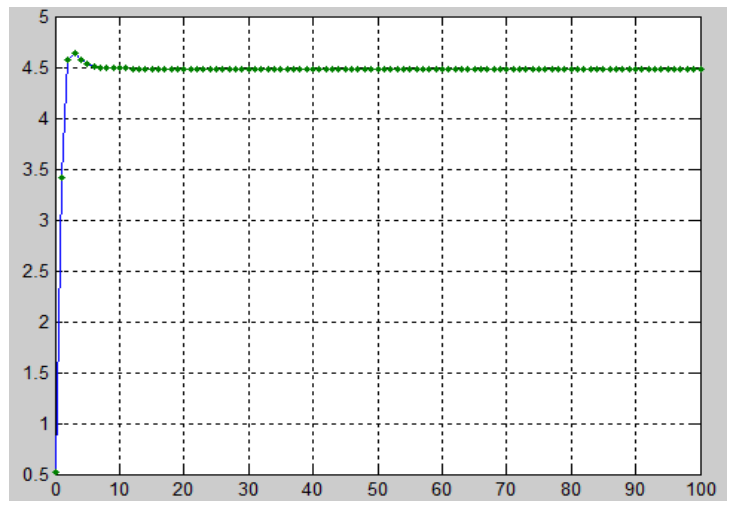

Figure 35: Orbit of $F(z)$ at $s=s^{\prime}=1, n=3$ for $z_{0}=0.5234$ 0.6319i 
Table 4: Orbit of $F(z)$ at $s^{\prime}=s^{\prime}=1, n=3.5$ for $z_{0}=0.5234$ $0.6319 i$

\begin{tabular}{|c|r|c|c|}
\hline No. of iteration & \multicolumn{1}{|c|}{$|\mathrm{F}(\mathrm{z})|$} & No. of iteration & $|\mathrm{F}(\mathrm{z})|$ \\
\hline 1 & 0.8205 & 12 & 6.5976 \\
\hline 2 & 3.2012 & 13 & 6.6015 \\
\hline 3 & 4.366 & 14 & 6.6035 \\
\hline 4 & 5.3174 & 15 & 6.6046 \\
\hline 5 & 5.9097 & 16 & 6.6051 \\
\hline 6 & 6.2369 & 17 & 6.6054 \\
\hline 7 & 6.411 & 18 & 6.6056 \\
\hline 8 & 6.5028 & 19 & 6.6057 \\
\hline 9 & 6.5512 & 20 & 6.6057 \\
\hline 10 & 6.5769 & $\mathbf{2 1}$ & $\mathbf{6 . 6 0 5 8}$ \\
\hline 11 & 6.5904 & 22 & 6.6058 \\
\hline
\end{tabular}

After21 iterations the value converges to a fixed point.

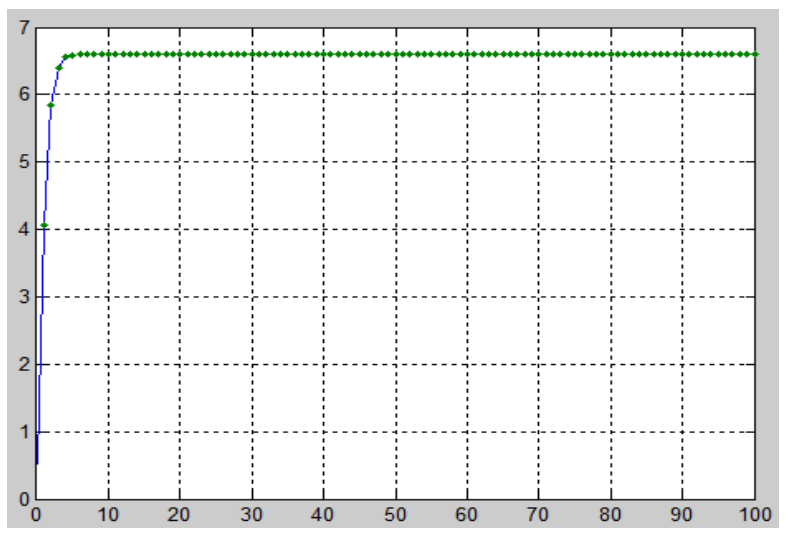

Figure 36: Orbit of $F(z)$ at $s^{\prime}=s^{\prime}=1, n=3.5$ for $z_{0}=0.5234$ $0.6319 \mathrm{i}$

5.3 Fixed points of Bi-quadratic polynomials Table 5: Orbit of $F(z)$ at $s=s^{\prime}=1, n=4$ for $\mathrm{z}_{0}=\mathbf{0 . 4 2 3 6 1 1 + 0 . 0 1 3 8 8 \mathrm { i }}$

\begin{tabular}{|c|c|c|c|}
\hline No. of iteration & $|\mathrm{F}(\mathrm{z})|$ & No. of iteration & $|\mathrm{F}(\mathrm{z})|$ \\
\hline 1 & 0.4238 & 12 & 8.6053 \\
\hline 2 & 3.1621 & 13 & 8.6092 \\
\hline 3 & 4.6181 & 14 & 8.6111 \\
\hline 4 & 6.1321 & 15 & 8.6119 \\
\hline 5 & 7.2585 & 16 & 8.6123 \\
\hline 6 & 7.9297 & 17 & 8.6125 \\
\hline 7 & 8.2825 & 18 & 8.6126 \\
\hline 8 & 8.4563 & 19 & 8.6126 \\
\hline 9 & 8.5394 & 20 & 8.6126 \\
\hline 10 & 8.5785 & $\mathbf{2 1}$ & 8.6127 \\
\hline 11 & 8.5967 & 22 & 8.6127 \\
\hline
\end{tabular}

After 21 iterations the value converges to a fixed point

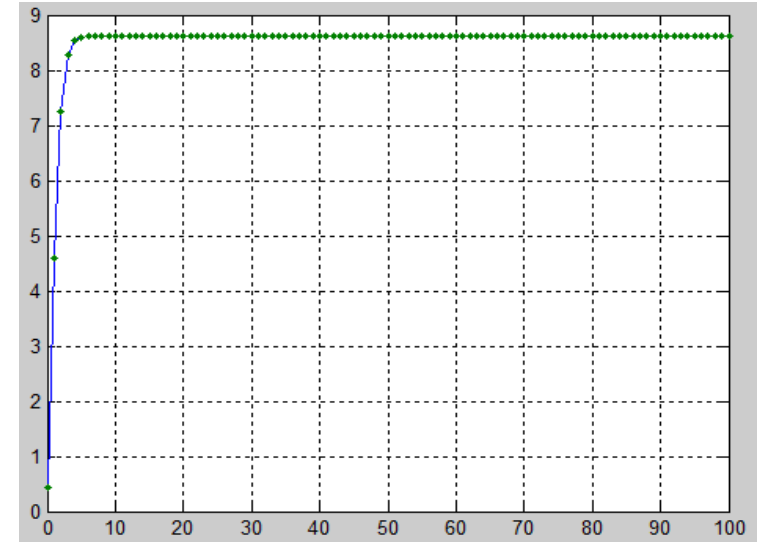

Figure37: Orbit of $F(z)$ at $s=s^{\prime}=1, n=4$ for $\mathrm{z}_{0}=\mathbf{0 . 4 2 3 6 1 1 + 0 . 0 1 3 8 8 \mathrm { i }}$

Table 6: Orbit of $F(z)$ at $s=s^{\prime}=1, n=4.5$ for $\mathrm{z}_{0}=\mathbf{0 . 4 2 3 6 1 1 + 0 . 0 1 3 8 8 \mathrm { i }}$

\begin{tabular}{|c|c|c|c|}
\hline No. of iteration & $|\mathrm{F}(\mathrm{z})|$ & No. of iteration & $|\mathrm{F}(\mathrm{z})|$ \\
\hline 1 & 0.4238 & 11 & 10.6305 \\
\hline 2 & 3.1638 & 12 & 10.6367 \\
\hline 3 & 5.1799 & 13 & 10.6394 \\
\hline 4 & 7.4033 & 14 & 10.6405 \\
\hline 5 & 9.0093 & 15 & 10.641 \\
\hline 6 & 9.8923 & 16 & 10.6412 \\
\hline 7 & 10.3129 & 17 & 10.6412 \\
\hline 8 & 10.5002 & $\mathbf{1 8}$ & $\mathbf{1 0 . 6 4 1 3}$ \\
\hline 9 & 10.5813 & 19 & 10.6413 \\
\hline 10 & 10.6158 & 20 & 10.6413 \\
\hline
\end{tabular}

After 18 iterations the value converges to a fixed point

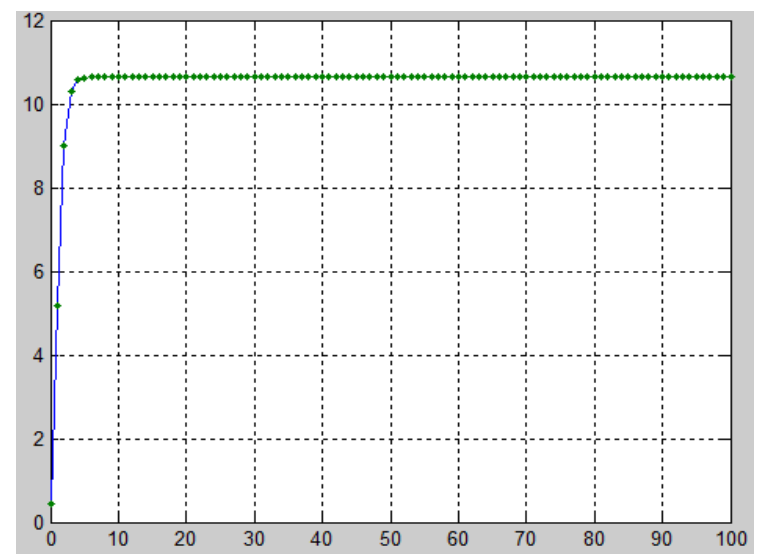

Figure 38: Orbit of $F(z)$ at $s^{\prime}=s^{\prime}=1, n=4.5$ for $z_{0}=0.423611+$ 0.01388i

\section{CONCLUSION}

In the complex dynamics logarithmic polynomial function $\mathrm{z} \rightarrow$ $\log \left(z^{n}+c\right)$, where $n>=2$. The fractals generated with power $n$ are found as rotationally symmetric. There are ovoids or bulbs attached with main body. The number of major secondary lobe 
is $(n-1)$. For higher values of $n$, the central body is bifurcated into (n-1) lobes from left side.

For non integer values, the new lobe is created step by step as it passes to upper integer (ceil) value. From observation and figure shown above, i.e. for $n=2$, number of lobe is $1(n-1)$, as the value of $\mathrm{n}$ is increased to $2.4,2.8$, the new lobe is created slowly, and for $n=3$ there are 2 lobes created from the left portion. So the bifurcation process is seen clearly during noninteger values. The fractals generated are symmetrical along the $\mathrm{x}$-axis. We obtained fixed point for quadratic function after 42 iterations, for cubic function after 30 and for bi-quadratic function after 21 iterations. Similarly we obtained fixed point for $n=2.5$ after 122 iterations, for $n=3.5$ after 21 iterations and for $n=4.5$ after 18 iterations.

\section{REFERENCES}

[1] Mandelbrot, Benoit B., "The fractal geometry of nature." Macmillan. ISBN 978-0-7167-1186-5, 1983.

[2] Barnsley, Michale F., Devaney, Robert L., Mandelbrot, Benoit B., Peitgen, Heinz-Otto, Saupe, Dietmar and Voss, Richard F., "The Science of Fractal Images", Springer Verlag 1988.

[3] Batty, Michael ,"Fractals - Geometry Between Dimensions," New Scientist (Holborn Publishing Group) 105 (1450): 31, 1985-04-04.

[4] Negi, Ashish, "Generation of Fractals and Applications", Thesis, Gurukul Kangri Vishwavidyalaya, 2005.

[5] Mandelbrot, Benoit B., "Fractals and Chaos" Berlin: Springer. pp. 38, ISBN 978-0-387-20158-0. "A fractal set is one for which the fractal (Hausdorff-
Besicovitch) dimension strictly exceeds the topological dimension", 2004.

[6] Edgar, Gerald, "Classics on Fractals", Boulder, CO: Westview Press. ISBN 978-0-8133-4153-8, 2004.

[7] Agarwal Shafali and Negi, Dr.Ashish, "Midgets of Transcendental Superior Mandelbar Set", International Journal of Computer Science Issues (IJCSI), Vol. 9, Issue 4, No.3, July 2012

[8] Negi, Ashish and Rani, Mamta, "Midgets of Superior Mandelbrot Set", Chaos, Solitons and Fractals, July 2006.

[9] Chauhan,Y.S., Rana R. and Negi, Ashish, "New Julia Sets of Ishikawa Iterates", International Journal of Computer Applications (IJCA), Volume 7, No.13, October 2010.

[10] Ishikawa, S, "Fixed points by a new iteration method", Proc. Amer. Math. Soc.44, (1974), pp.147-150.

[11] Chauhan,Y.S. Rana R. and Negi, Ashish, "New Tricorn \& Multicorns of Ishikawa Iterates", International Journal of Computer Applications (IJCA), Volume 7, No.13, October 2010 .

[12] Rana, R., Chauhan Y.S. and Negi, Ashish , "Ishikawa Iterates for Logarithmic function", International Journal of Computer Applications (IJCA), Volume 15, No.5, February 2011.

[13] Daveney, R.L., "An Introduction to Chaotic Dynamical Systems ”, Springer-Verlag, New York. Inc.1994.

[14] Devaney, Robert L., "A First Course in Chaotic Dynamical Systems: Theory and Experiment", Addison-Wesley, MR1202237, 1992.

[15] Peitgen H. and Richter P.H., "The Beauty of Fractals", Springer-Verlag, Berlin, 1986. 